\title{
DISTRIBUTION, COEXISTENCE, AND COMPETITION OF WHIRLIGIG BEETLES ${ }^{1}$
}

\author{
Conrad A. Istock ${ }^{2}$ \\ Department of Zoology, University of Michigan, Ann Arbor
}

Accepted October 18, 1965

At present we know very little about the degree to which similar species, occurring together, may overlap in their utilization of a given array of resources. Larkin (1956) has suggested that this overlap may be great among freshwater organisms, particularly fish. MacArthur (1958) concluded that the opposite was true among birds of the north temperate zone.

Restriction of ecological overlap would presumably arise from interspecific competition and it has been claimed that interspecific competition is a frequent consequence of the manner in which natural communities are organized (Hairston $e t$ al., 1960). Therefore, attempts to generalize about the diversity and relative abundance of species in a community or in a single trophic level might logically proceed from reasoning about how resources are apportioned through competition (MacArthur, 1957, 1960; Hairston, 1959). The effectiveness of this approach would be enhanced if definite statements about the relationship of interspecific competition and the division of resources among species could be derived from nature. The fact that some ecologists (Andrewartha and Birch, 1954; Thompson, 1956) have been unable to accept competition as an integral feature of community organization further indicates a need for specific field studies.

The concept of interspecific competition has been derived in four, rather distinct ways: (1) theoretical investigations (Lotka,

\footnotetext{
${ }_{1}$ This paper is part of a thesis submitted to the University of Michigan for the degree of Doctor of Philosophy. The complete field and laboratory data are available in the thesis appendix or on microfilm from University Microfilms, Ann Arbor, Michigan.

${ }^{2}$ Present address: Department of Biology, University of Rochester, Rochester, New York.
}

1925, 1932; Volterra, 1926; Gause, 1934; Gause and Witt, 1935; Winsor, 1934; Hutchinson and Deevey, 1949); (2) laboratory experimentation (Gause, 1934; Gause et al., 1934; Park, 1948, 1954, 1957; Crombie, 1945, 1946; Birch, 1953; Utida, 1953; Frank, 1952, 1957; Mučibabić, 1957a, 1957b); (3) observation of local species distributions (Tansley, 1917; Broadhead, 1958; Williams, 1963); and (4) studies concerning the evolution of modern species (Lack, 1947; Bowman, 1961; Ross, 1962; Mayr, 1963).

A clear understanding of what is meant by the term interspecific competition has been achieved as a result of the variety of endeavors just summarized, and Birch (1957) has composed a verbal definition. Birch correctly insisted on a strict meaning for the term and offered the following definition: "Competition between animals occurs when a number of animals (of the same or of different species) utilize common resources the supply of which is short. . .."

Interspecific competition then, refers to the interactions occurring between two or more species populations when they attempt to persist in the same place despite an overlap in their utilization of the same, limiting (insufficient) environmental resources. The ideas of "overlap" and "limiting" are crucial. However transient the periods of ecological overlap and resource limitation may be, they constitute competitive situations.

A striking feature emerging from the whole gamut of studies involving interspecific competition is the elusiveness of this interaction in nature. It is very difficult to recognize and even more difficult to demonstrate competition. IVhile theoretical 
and experimental studies of competition have achieved considerable sophistication, there is a dearth of accompanying definitive demonstrations of the same phenomenon in natural situations (Solomon, 1957). The definition of competition is based primarily upon the clarifications and simplifications of the theoretical and experimental studies. Insistence upon satisfying the conditions of "overlap" and "limiting" make the requirement for definitive field demonstrations indeed stringent and as yet mostly unachieved. The difficulties are attributable to problems encountered in attempting to obtain sufficiently rigorous control and replication in intricate natural environments. Without such control, we are unable to distinguish independent life history phenomena from interacting life history phenomena. This point can be made more clearly. Suppose we study the success of a particular species in a number of distinct but similar places and wish to explain those where it is less successful or absent as the result of competition with another species. We encounter the difficulty that these situations we wish to explain by invoking competition may merely contain deleterious characteristics, other than competitors, which make them less suitable or definitely unsuitable. Park (1948, 1954) has pointed out that the first step in any laboratory study of interspecific competition is to demonstrate that each of the species, when alone, can inhabit the experimental environment indefinitely. Despite increased difficulties, field studies should attempt to satisfy the same requirement. It is unlikely that field observation by itself can ever fully resolve these difficulties.

In field studies the difficulties encountered in demonstrating resource limitation and the overlapping utilization of such resources are usually circumvented by reasoning from the natural history of the species. This initial step dictates that all the subsequent information gathered will be to some degree circumstantial, since resource limitation and competition have thus been assumed, not proven. Connell's
(1959) study of two species of intertidal barnacles differs in that it satisfies these initial requirements and demonstrates competition experimentally in the field. Therefore, his use of competition for space as an explanation of the zonation of these species gains complete validity. In other work, such as the studies of the downstream distribution of triclad species by Beauchamp and Ullyott (1932), the use of competition as an explanation for distributional patterns seems reasonable but not completely rigorous. The same can be said about various field studies of salamanders (Hairston, 1951), Paramecium (Hairston, 1958), wood warblers (MacArthur, 1958), freshwater isopods (Williams, 1963), psocids (Broadhead, 1958), and the present study as well.

\section{Description of the Study}

The family Gyrinidae contains many abundant species which are frequently found together in the same place. These associations regularly involve the coaggregation of two to 12 species representing two genera. Attention was first called to this situation by LeConte (1868). Fall (1922) listed a few cases of coassociation among species of Gyrinus and commented that this was the rule in eastern North America. This paper deals with the competitive implications of the apparently simpler situation found among the species of Dineutes. Three species are considered throughout the paper: $D$. horni Rbts., $D$. nigrior Rbts., and $D$. assimilis Kby.

Field investigations were designed to determine the ubiquity of these situations of coassociation and to see if distributional patterns offered any indication that the species interact with one another. Laboratory experiments were designed to force larval Dineutes into competition for food, since it appeared likely that the larvae encounter food limitation in nature. The competition experiments have some inherent points of interest, but it is also thought that they may indicate mechanisms and outcomes of competition similar to those 


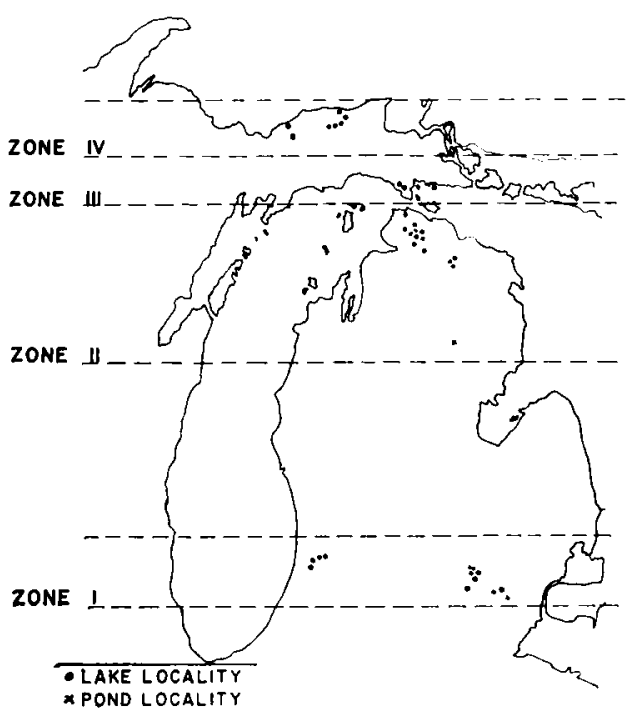

FIG. 1. Collecting pattern within Michigan; lake localities, pond localities, and collecting zones are shown.

ocurring among natural populations of these insects.

\section{Methods and Materials}

In 1962 and 1963 field collections were made in Michigan along a 350 mile northsouth distance. Collecting effort was concentrated in four zones (Fig. 1) extending from the southern part of the state to the shore of Lake Superior in the northeastern part of the Upper Peninsula. Zones I and IV constitute the extremities of the area under study, while Zone II is about twothirds of the way from the southern end to the northern end. The Straits of Mackinac separate Zone II from Zone III. This separation is arbitrary and is made only because it emphasizes several features of the field data.

Thirty-seven localities are considered in all: eight lakes and five ponds in Zone I; 10 lakes and four ponds in Zone II; two lakes in Zone III; seven lakes in Zone IV. Three of the small permanent ponds (referred to as Burt, Crane, and Nixon Road) in Zone I were followed closely in 1963. In the Burt and Crane pond studies it was possible, for the most part, to census the populations for composition and then return the beetles to the ponds. Only the last collections for the summer were killed and preserved.

Throughout the study only lentic habitats were considered. The ponds were all of less than seven acres (usually much less) and the lakes were all larger than seven acres (always much larger).

All field collections were made by dip netting adult beetles from the surface of the water. It is virtually impossible for the collector to bias the species compositions of his collections because the species are not easily identified by inspection in the field.

Imagoes of the species of Dineutes were identified according to the descriptions of Roberts (1895) and Hatch (1930). The larvae used in the laboratory experiments were readily identifiable because of differences in head pigmentation as described by Hatch (1927).

Recently pupated imagoes (tenerals) are recognizable by the softness of the exoskeleton. Teneral individuals are not capable of flight, thus the finding of such an individual at a particular place demonstrates completion of the life cycle by that species. Reproductive imagoes will be referred to as "old generation" individuals, whereas their teneral progeny will be designated as the "new generation."

\section{Experimental Procedures}

Larvae of Dineutes can be grown from hatching through pupation using the large, red larvae (bloodworms) of midges (Chironomidae $=$ Tendipedidae) as food. Throughout this paper the term larvae refers to Dineutes larvae; the term bloodworm is used to designate the food supplied to the gyrinids during the experiments.

Supplies of synchronously developing Dineutes larvae were obtained from female beetles confined in small, water-filled, styrofoam buckets for two and a half days. By previously separating the females by species, monospecific egg cultures were obtained. This method also allowed the 
estimation of egg production. The time required for pre-hatching development is the same in all three species. Hence all eggs collected on the same day hatched on the same day, making it possible to start competition experiments with all the larvae in the first day of life.

Finger bowls of two sizes were used in the experiments. The smaller size had a diameter of $10.5 \mathrm{~cm}$. and the larger bowls a diameter of $19.5 \mathrm{~cm}$. The larger bowls had the advantage that the water rarely fouled and was therefore usually changed only once in the course of an experiment. Bloodworms of a medium size (17 to 23 $\mathrm{mm}$.) were consistently used. Food levels of two, six, or 12 bloodworms per day were used in intraspecific experiments. The food level of six per day was used in the interspecific experiments. If bloodworms were left alive in the dish from the previous day they were used to make up the quota of food for the next day. The amount of uneaten food, if any, was recorded for each day; dead but uneaten bloodworms or portions of bloodworms were recorded as uneaten food but removed from the dish. The red color of the bloodworm hemolymph made fractional estimates of food consumption possible. At the same time that the food was introduced each day, the number of live Dineutes larvae was recorded. Any dead larvae were removed.

Conditions of constant temperature and uniformly repeating photoperiod (16 hours of light, eight hours of dark) were maintained. Indirect light was provided by shielded fluorescent tubes. Censusing and feeding were carried out at about noon of each day, approximately the middle of the lighted part of the photoperiod.

The growth rates of single, isolated larvae were determined at room temperature. In this case, isolated individuals of each of the species were reared simultaneously to produce comparable growth rate data. These single isolates were provided with abundant food.

The graphical representations of the interspecific competition experiments (Figs.
14 and 15) involve a quantity termed "per cent progress." This is merely a method for plotting a number of experiments on the same axes despite differing inital relative concentrations. The following example indicates how per cent progress is calculated. Suppose the experiment starts with 35 per cent of the initial larvae belonging to the species which will eventually "win." Further suppose that in the first time interval this species suffers a smaller proportion of the total mortality than the other species, and now comes to form 41.5 per cent of the total number of larvae still alive. It has increased in percentage representation by 6.5 per cent. The total possible percentage increase available to this species, if it entirely excludes the other species, is 65 per cent (from 35 per cent to 100 per cent). During the first time interval it went 10 per cent of the way (6.5 per cent $/ 65$ per cent $\times 100=10$ per cent). This 10 per cent was its per cent progress for the first time interval. A similar calculation may be done for each succeeding time interval.

\section{Continental Distribution}

The broad distributions of Dineutes horni, Dineutes nigrior, and Dineutes assimilis are only roughly known. The distributions outlined by Roberts (1895) and Hatch (1930) are still the most complete, and have been combined in Fig. 2. The ranges of all three species are confluent from Maine to Virginia on the Atlantic coast and from the eastern Dakotas and western Iowa to southern Illinois on the west. The broad area of overlap so defined is only a crude approximation. If it is in error it probably overestimates the southward and westward boundaries of the area of confluence.

\section{Natural History of Gyrinidae}

The natural history of the Gyrinidae is discussed in some detail by Balfour-Browne (1950). Natural history information may also be gleaned from Miall (1895), Wilson (1923), Hatch (1925), Butcher (1930), and Balduf (1935). 


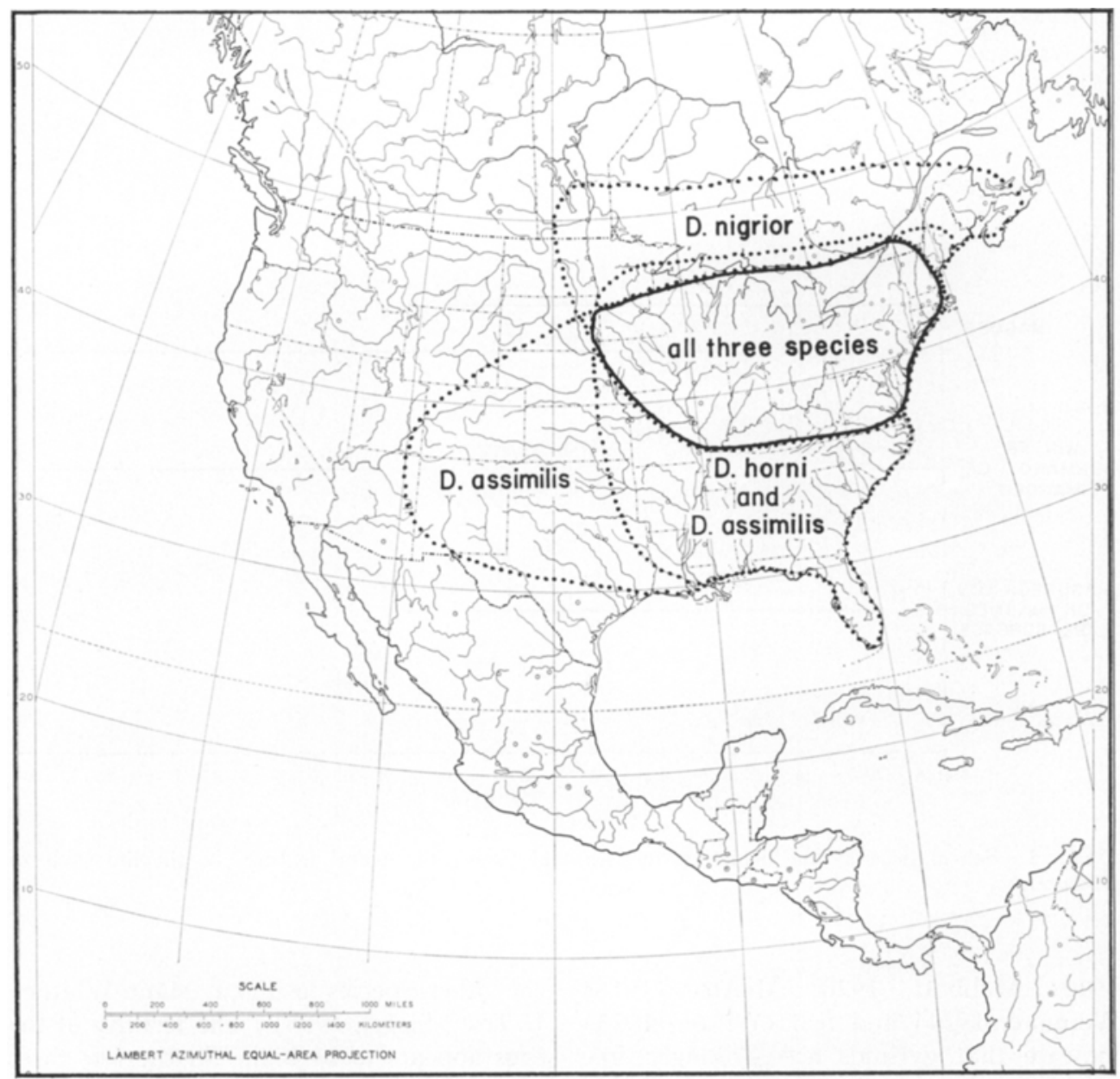

Fic. 2. Continental distributions of three species of Dineutes showing areas of geographical confluence.

The life cycle of Dineutes includes four major stages: (1) eggs attached to underwater objects; (2) larvae which live entirely beneath the water surface among the submerged vegetation; (3) terrestrial pupae within a pupal case constructed by the larva; and (4) adults which live almost entirely on the surface of the water.

The approximate seasonal timing of the life cycle of Dineutes at latitudes of $40^{\circ}$ to $50^{\circ} \mathrm{N}$ is shown in schematic form in Fig. 3. In May, when water temperatures reach about $18^{\circ} \mathrm{C}$., copulation begins and oviposition follows shortly. D. nigrior and
$D$. assimilis begin breeding about a week earlier than $D$. horni (in southern Michigan). The breeding season of horni and nigrior is surprisingly long, extending into August. Dineutes assimilis has a much shorter breeding season, which terminates by early July. In middle and late summer adults of the new generation also breed, but to a very reduced degree. Longevity has not been satisfactorily determined in these beetles but it is generally thought that they live for only one year (BalfourBrowne, 1950).

Studies of the food habits of birds (Beal, 


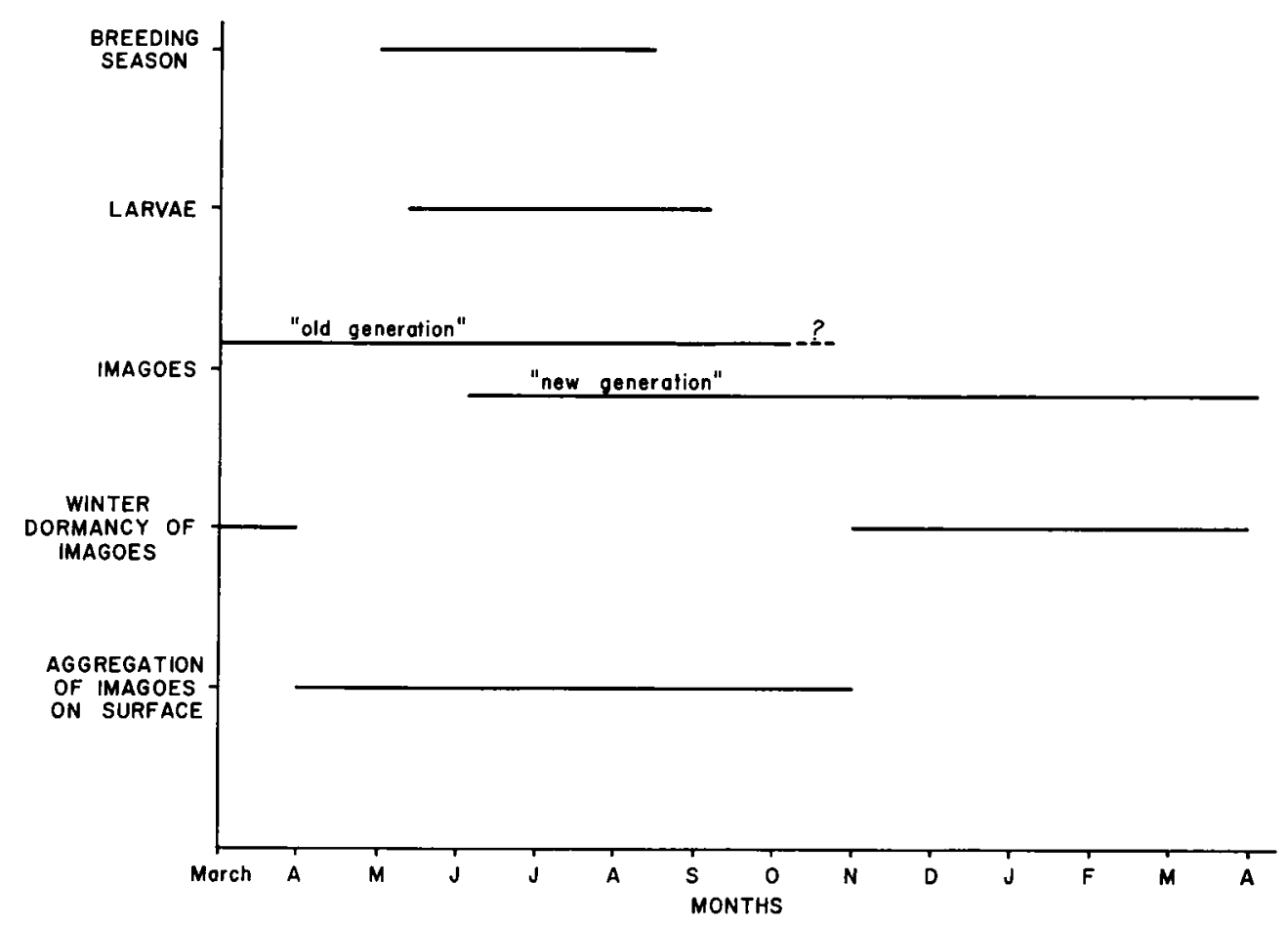

FIG. 3. Schematic diagram depicting the seasonal timing of several features of the life cycle of Dineutes.

1912; Mabbott, 1920; McAtee, 1918; Wetmore, 1924) and fish (Wilson, 1923) indicate that gyrinids are strikingly free of these predators. Impunity to predators has been attributed to the "repugnatorial gland" (Balfour-Browne, 1950). There is no evidence concerning other potential sources of predation.

\section{Fecundity AND Fertility}

A series of estimates of egg production were obtained from field captured, old generation females. These are shown in Table 1. In calculating these means the late July estimates, which mark the close of the breeding season, were disregarded. These mean figures are indicative of the daily egg productions of the species for most of the breeding season. The differences among these estimates are not significant when the means for each species are tested against the mean for each of the other species using a Mann-Whitney U Test (Siegel, 1956). The fertility of the eggs appears to be high. In the few cases where an attempt was made to determine fertility, it was 90 per cent or greater.

\section{LaRval Growth Rate}

The growth and development of the larvae of $D$. horni and $D$. nigrior are nearly identical. Data from well-fed, isolated larvae of these two species are plotted in Fig. 4. Comparable data for assimilis were not obtained. However, the molting rate of assimilis is indicated by sharp dips in

TABle 1. Mean egg production.

\begin{tabular}{lcc}
\hline \hline Species & Eggs/9 day & Standard error \\
\hline D. horni & 12.10 & \pm 1.2 \\
$D$. nigrior & 14.71 & \pm 2.7 \\
D. assimilis & 16.93 & \pm 5.3 \\
\hline
\end{tabular}




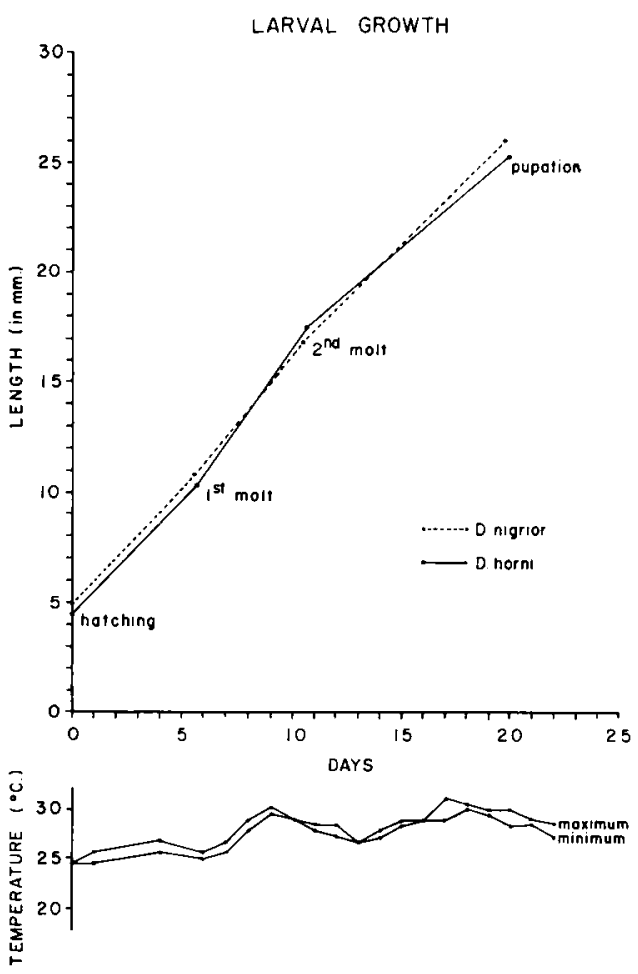

FiG. 4. Growth and molting of D. horni (15 individuals) and $D$. nigrior (18 individuals) at room temperatures.

the food consumption curves for some of the intraspecific competition experiments in Fig. 13. These data show that assimilis is very much like the other two species in its larval growth.

\section{LARVAL BeHAVIOR UNDER LABORATORY Conditions}

In the latter part of the first day after hatching the larvae will feed readily upon encountering a bloodworm. For a brief period (less than six hours) after the onset of feeding there is little or no interaction between larvae. Aggressive behavior between larvae can be observed by the end of the first 24 hours. A "hungry" larva at any age will engage in a vigorous attack and will readily follow through with attempts at predation or cannibalism. Wellfed larvae are always much more passive.
TABLE 2. Relative abundances of three species of Dineutes in Michigan lakes.

\begin{tabular}{lccc}
\hline Zone & D. horni & D. nigrior & D. assimilis \\
\hline I & $91.5 \pm 3.0^{*}$ & $4.2 \pm 2.3$ & $5.7 \pm 1.7$ \\
& $88.4 \dagger$ & 5.9 & 4.3 \\
II & $77.6 \pm 6.6$ & $16.1 \pm 5.2$ & $6.3 \pm 3.5$ \\
& 81.1 & 14.6 & 4.3 \\
III & $47.8 \pm 19.8$ & $42.0 \pm 26.5$ & $11.2 \pm 6.6$ \\
& 35.0 & 57.8 & 7.2 \\
IV & $17.8 \pm 8.1$ & $82.2 \pm 8.1$ & 0.0 \\
& 27.8 & 72.2 & 0.0
\end{tabular}

* The upper percentage in each entry is the mean relative abundance \pm standard error calculated from the relative abundances for the individual localities in each zone.

$\dagger$ The lower percentage in each square is the relative abundance calculated from the total number of beetles of each species for the whole zone.

\section{Field Distribution Patterns}

Distribution of Dineutes Species by Lakes

The collections gathered in 1962 and 1963 from lakes reveal a fairly clear pattern. Table 2 presents estimates of relative abundance for the three species of Dineutes. These estimates have been calculated in two different ways for each of the four zones. One estimate in each case is the mean of the relative abundances calculated individually for each lake in the zone. The other estimate was obtained by first totaling the beetles of each species for the whole zone and then computing a single relative abundance for each species. This technique is suggested by Snedecor (1956) as a check on the validity of means calculated from percentage data. These data are illustrated in Fig. 5.

The predominant species to the north (Zone IV) is Dineutes nigrior, while $D$. horni predominates to the south (Zone I). The intervening areas offer intermediate expressions. D. assimilis is rarely abundant and disappears entirely in the northernmost collections.

The lake data for $D$. nigrior and $D$. horni indicate that the area studied is a region of overlap and transition between a northern and a southern species. This is 


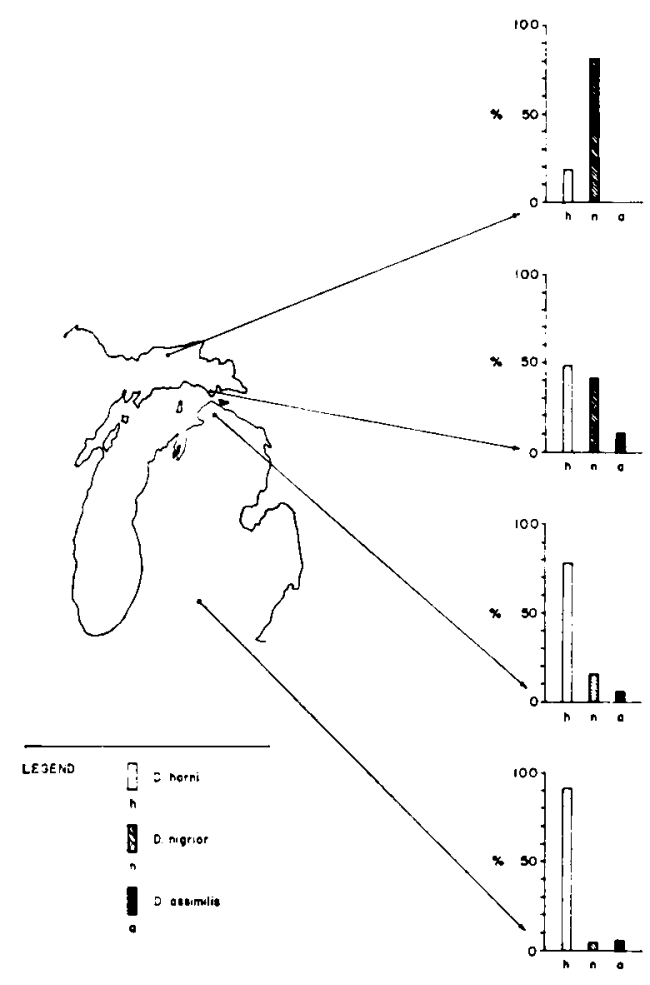

Fig. 5. Mean relative abundance histograms for the four Michigan collecting zones.

in accord with the continental distributions of these species. The transition from horni in the south to nigrior in the north is gradual and incomplete. In some northern lakes both these species are common. In a number of lakes both horni and nigrior are known to have completed reproduction while in coassociation. In 1965 a lake in Zone IV was found which contained over 90 per cent horni.

Distribution of Dineutes Species by Ponds

Table 3 presents the mean relative abundance data from nine ponds in Zones $\mathrm{I}$ and II. Dineutes nigrior is more successful in developing substantial populations in ponds of Zones $I$ and II than is $D$. horni, although there is a clear exception to this (Pond 2-Crane Pond). Dineutes assimilis is also better represented in ponds, although its success is more sporadic. Three of the ponds (Burt, Crane, and
TABLE 3. Relative abundances (in per cent) of three species of Dineutes in Michigan ponds (1962 and 1963).

\begin{tabular}{lrrr}
\hline \hline Pond number & D. horni & D. nigrior & D. assimilis \\
\hline ZONE I & & & \\
1 (Burt) & 0.9 & 87.5 & 11.6 \\
2 (Crane) & 86.5 & 11.3 & 2.2 \\
3 (Nixon Road) & 5.1 & 11.3 & 83.6 \\
$4^{*}$ & 12.5 & 68.8 & 18.7 \\
$5^{*}$ & 1.6 & 62.3 & 36.1 \\
ZONE II & & & \\
$6^{*}$ & & & \\
$7^{*}$ & 9.5 & 90.5 & 0.0 \\
$8^{*}$ & 10.1 & 89.9 & 0.0 \\
$9^{*}$ & 19.7 & 70.4 & 9.9 \\
\hline
\end{tabular}

* Based on only one or two collections.

Nixon Road) from the southernmost zone present interesting contrasts. The data for these three ponds are presented as percentages because it is not possible to obtain area-based censuses. The total numbers taken at each of the censuses (shown at the top of each histogram in Figs 6, 7, and 8) offer an approximate indication of the changes in population size occurring through the spring and summer. This trend is the same in all three ponds and agrees with' the seasonal trend of population size recorded by Smith (1926) for a Massachusetts pond containing mostly $D$. assimilis (=americanus) and a few $D$. horni.

Burt Pond is a very small (less than half an acre), permanent, woodland pond. It is artificial but has developed an extensive flora and fauna. The relative abundances of the three species throughout the spring and summer of 1963 are shown in Fig. 6 (see Fig. 8 for legend). The pond supports both $D$. nigrior and $D$. assimilis and it was found (presence of teneral individuals) that both these species were able to complete reproduction simultaneously. $D$. horni occurred on the pond very infrequently, mainly in the early part of the season, and did not reproduce at all in this pond. Dineutes nigrior was the most successful species in terms of reproduction. It represented more than 80 per cent of the 
BURT POND CENSUSES - 1963

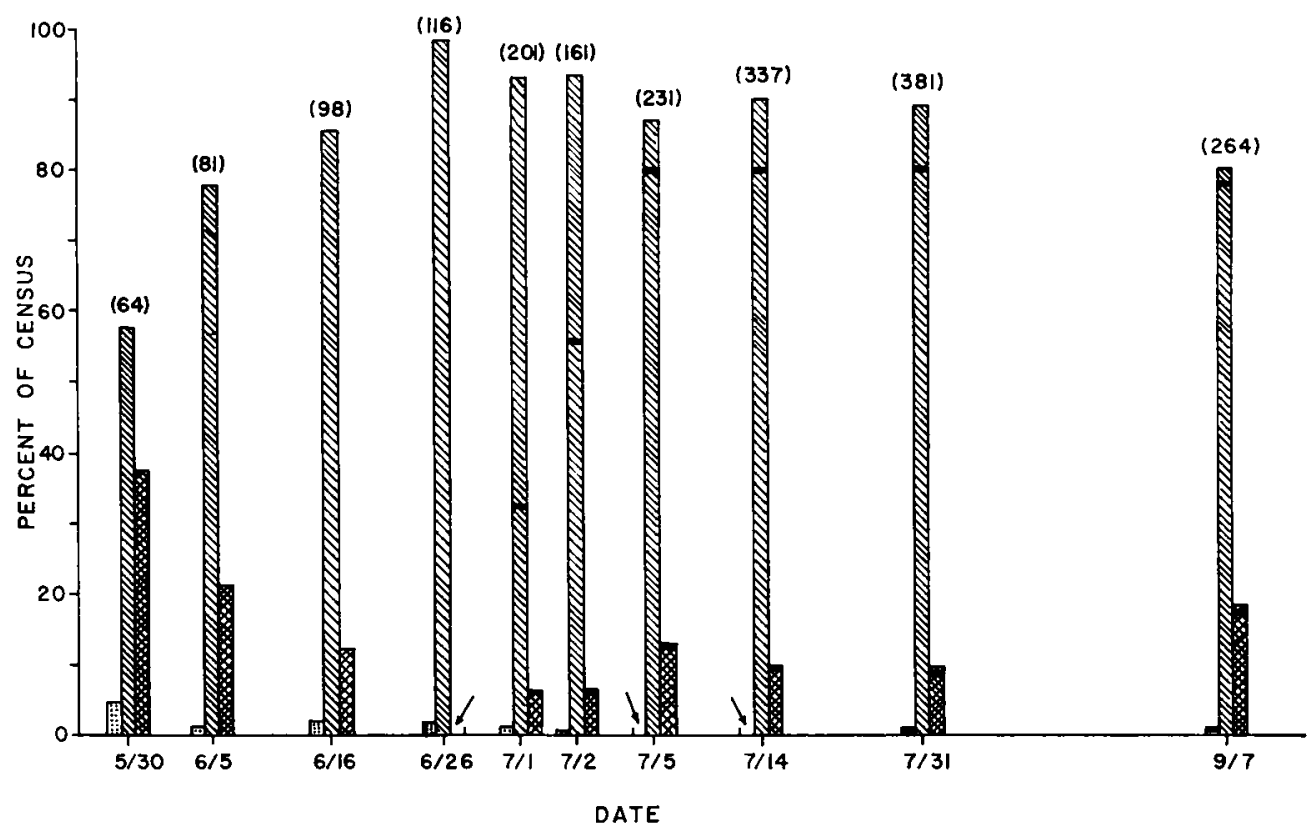

FIG. 6. Relative abundance histograms for Burt Pond. Based on censuses of imagoes throughout the 1963 breeding season. See Fig. 8 for legend.

population in the late summer as opposed to less than 60 per cent initially. Probably, there was emigration from the pond in the course of the summer. However, this cannot account for the numerical superiority of nigrior because the unequal representation of nigrior and assimilis also appears among the new recruits entering the population in July. The reproductive capacity of either species would have been sufficient to supply the total population of the pond (between 500 and 1000 in August and early September).

Crane Pond is a larger pond (two to three acres) located about one-half mile from Burt Pond. It is permanent, partially surrounded by woodland, and has a welldeveloped aquatic biota. Fig. 7 (see Fig. 8 for legend) illustrates the relative abundance data at this pond for the spring and summer of 1963. Here horni was the most abundant species; in fact it was essentially the only species present during the breeding period. In late summer nigrior and assimilis appeared in small numbers. The only teneral beetles found were horni, hence only horni reproduced in this pond.

Nixon Road Pond is similar in size to Crane Pond and lies in an open field. It is permanent and has a well-developed fauna and flora. Here the relative abundances in 1963 (Fig. 8) present a sharp contrast to those of both the preceding ponds. Only three collections were made, but they were spread so as to cover adequately most of the period discussed for Crane and Burt ponds. The dominant species was Dineutes assimilis both in overall numbers and reproductive success. However, teneral imagoes were found for all three species. No collection comparable to the early September collection in the other two ponds was possible because the beetles were entirely gone from the pond by this time.

The departure of all the Dineutes from Nixon Road Pond was a somewhat early expression of the situation observed in the 


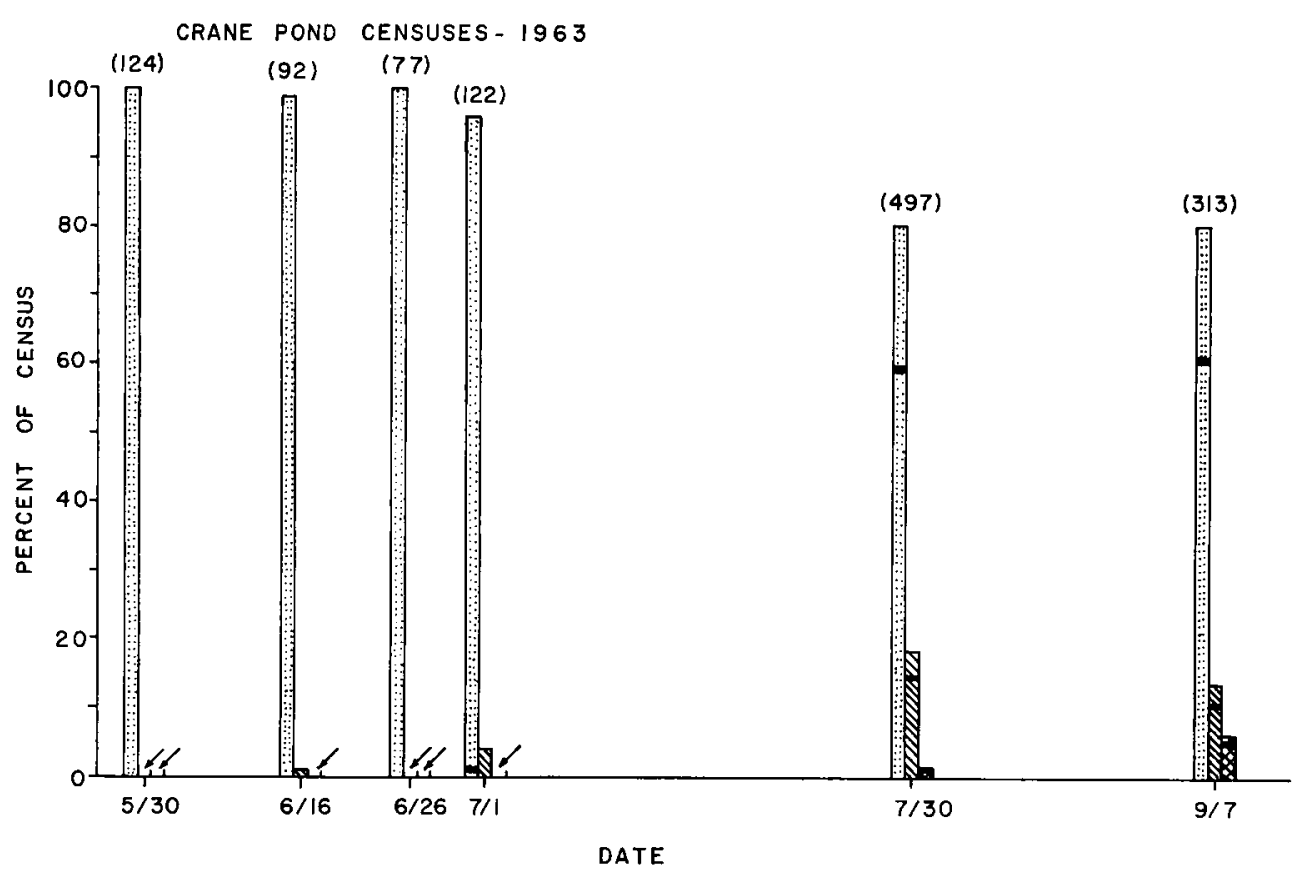

FIc. 7. Relative abundance histograms for Crane Pond. Based on censuses of imagoes throughout the 1963 breeding season. See Fig. 8 for legend.

other two ponds. It appears that species of Dineutes do not overwinter in the ponds but rather in lakes within the region. This corresponds with the observation that $D$. nigrior and $D$. assimilis are present in lakes in early spring and in late summer and fall. Hence it is likely that all three species overwinter in southern Michigan lakes, but that $D$. nigrior, $D$. assimilis, and some $D$. horni migrate to ponds for breeding, leaving $D$. horni as the usual breeding species in lakes.

The relative abundance patterns in Burt, Crane, and Nixon Road ponds in 1964 were the same as those just described for 1963. In addition, four Zone IV ponds visited in 1964 contained only nigrior.

Teneral individuals of two species were found in ponds other than Burt and Nixon Road as well as in some Zone IV lakes. These are the cases of coexistence which will be referred to subsequently.

In summary, the field data contain clear indications of habitat segregation among the three species but there are also many local instances which indicate coexistence.

\section{Competition in Experimental Populations of LaRvae}

Intraspecific Competition

A series of experiments was carried out to explore the population consequences of larval competition. Some of these experiments involved larval populations of only one of the three species of Dineutes-horni, nigrior, and assimilis. Table 4 outlines the intraspecific experiments. The small number of replicates is the result of limitations imposed by the large number of bloodworms and considerable space necessary for carrying out the experiments. Nevertheless, the raw data are extremely consistent and the experiments most crucial to the subsequent discussion were the ones with the most replicates. In an effort to make the most of the bloodworm supply some of the experiments were terminated intentionally when only one or two sur- 


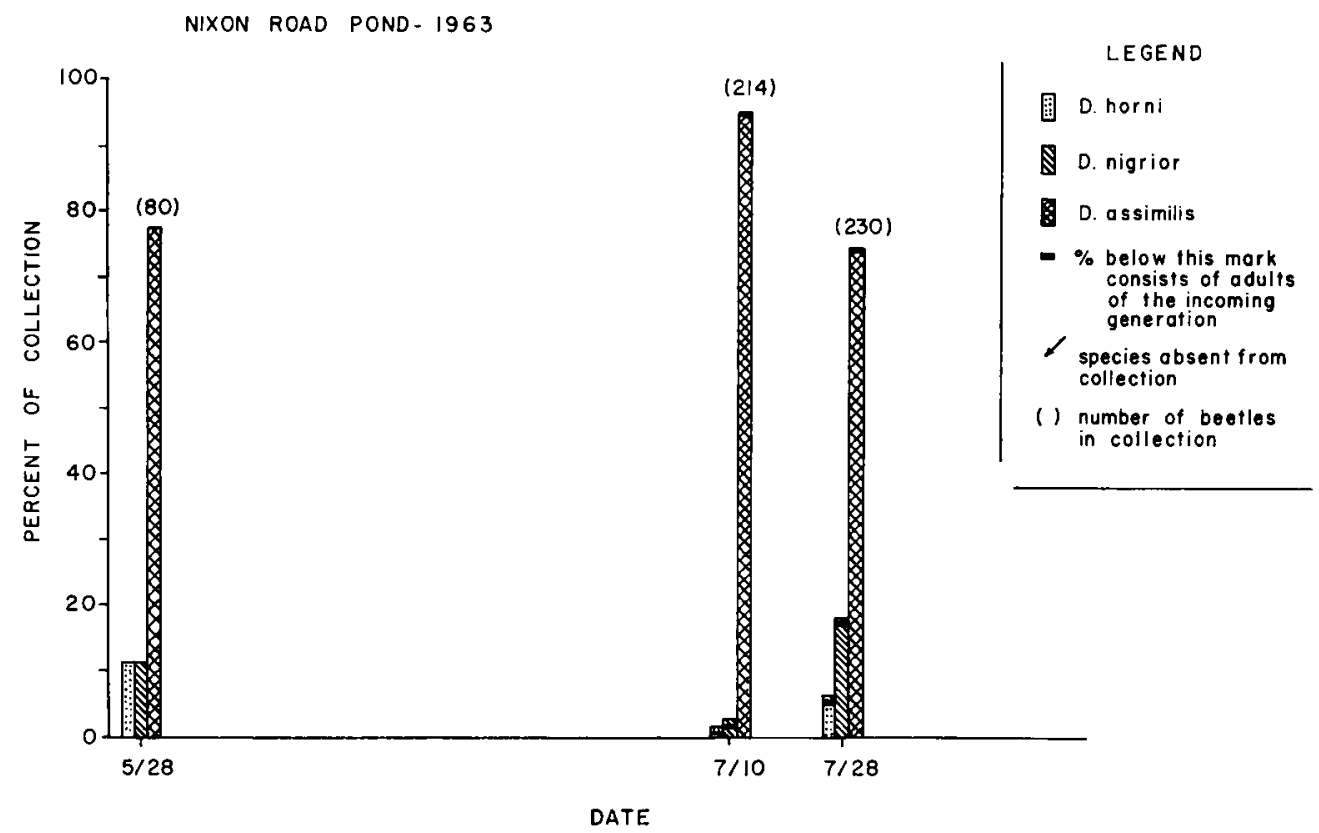

FIG. 8. Relative abundance histograms for Nixon Road Pond. Based on collections of imagoes. Includes the legend for Figs. 6, 7, and 8.

vivors remained. This is indicated by a " $T$ " on the graphs. In other cases the experiments were maintained until the survivors were ready to pupate, indicated by a "P" on the graphs.

The mean survivorship curves resulting from these experiments are illustrated in Figs. 9, 11, and 13. What is most important is that the survivorship curves reflect the food level imposed on the individual experiments. Fig. 9 includes six such curves (experiments I-VI, Table 4), three for $D$. horni and three for $D$. nigrior. Both species show a consistent response to the food supply. For each species high, medium, and low food levels correspond with the resulting high, medium, and low survivorship curves. From this it is concluded that in both of these species there exists a capacity for adjusting the population size to the food supply. It has already been pointed out that cannibalistic behavior is food-dependent in these larvae. Hence it is reasonable to suppose that population size is adjusted to the existing food supply, through cannibalism, as a function of the increasing food requirements for the growing larvae and the number of larvae present.

A further point apparent in Fig. 9 is that $D$. nigrior has a greater age-specific survival than $D$. horni at each food level.

TABLE 4. Description of experiments on larval intraspecific competition.

\begin{tabular}{llrlll}
\hline $\begin{array}{c}\text { Experi- } \\
\text { ment } \\
\text { num- } \\
\text { ber }\end{array}$ & $\begin{array}{l}\text { Spe- } \\
\text { cies }\end{array}$ & $\begin{array}{c}\text { Food } \\
\text { level } \\
\text { (blood- } \\
\text { worms } \\
\text { per } \\
\text { day) }\end{array}$ & $\begin{array}{c}\text { Tem- } \\
\text { pera- } \\
\text { ture } \\
\left({ }^{\circ} \mathrm{C} .\right)\end{array}$ & $\begin{array}{c}\text { Bowl size } \\
\text { (diam- } \\
\text { eter } \\
\text { in cm.) }\end{array}$ & $\begin{array}{c}\text { Num- } \\
\text { ber of } \\
\text { repli- } \\
\text { cates }\end{array}$ \\
\hline I & D. horni & 12 & 25 & 19.5 & 2 \\
II & $D$. horni & 6 & 25 & 19.5 & 2 \\
III & $D$. horni & 2 & 25 & 19.5 & 2 \\
IV & D. nigrior & 12 & 25 & 19.5 & 2 \\
V & D. nigrior & 6 & 25 & 19.5 & 4 \\
VI & D. nigrior & 2 & 25 & 19.5 & 5 \\
VII & $D$. nigrior & 6 & 25 & 10.5 & 2 \\
VIII & $D$. assimilis & 12 & 25 & 10.5 & 3 \\
IX & $D$. assimilis & 6 & 25 & 10.5 & 4 \\
X & $D$. assimilis & 12 & 20 & 10.5 & 2 \\
XI & $D$. assimilis & 6 & 20 & 10.5 & 2 \\
\hline
\end{tabular}




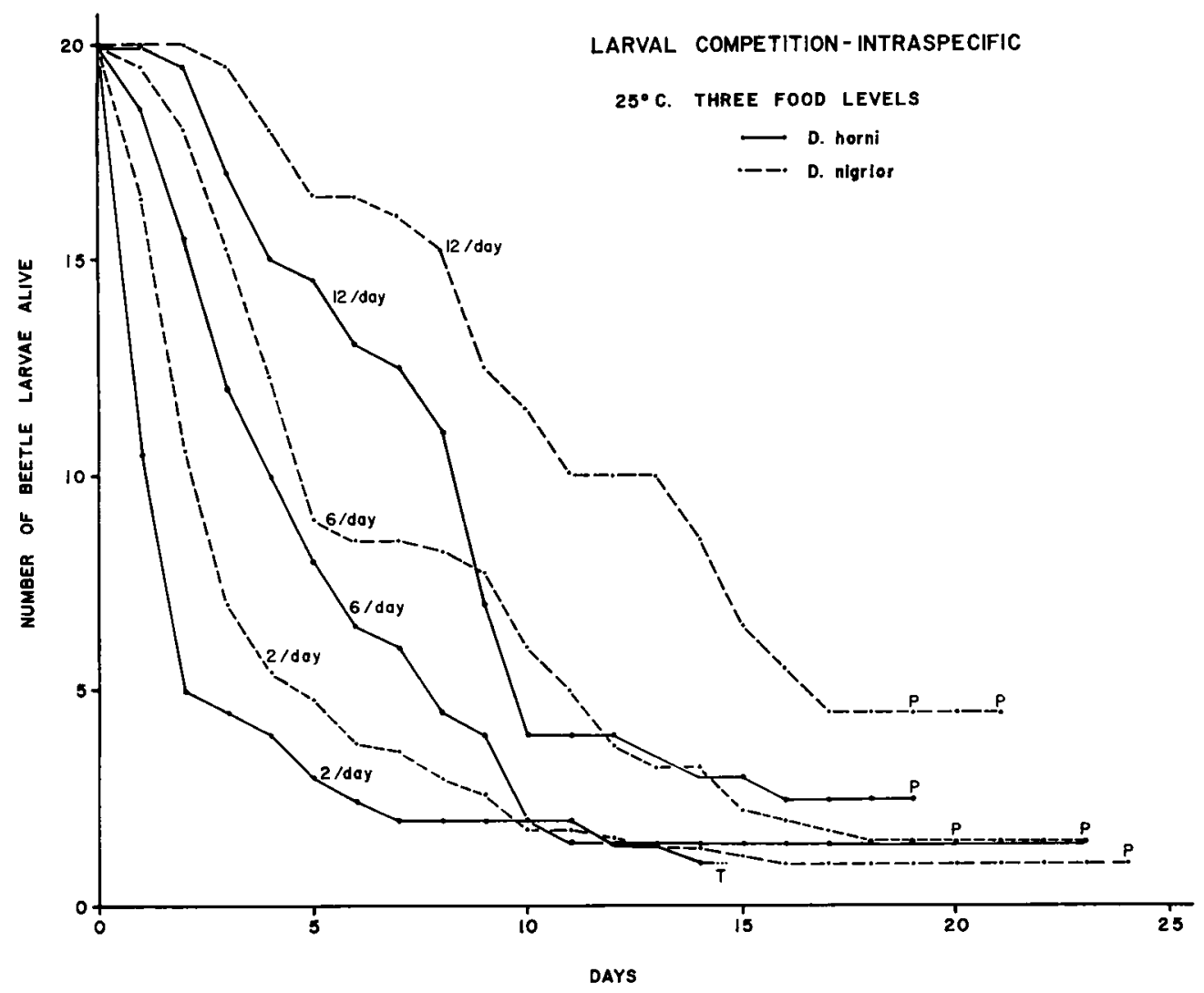

FIG. 9. Mean survivorship during intraspecific competition experiments with $D$. horni and $D$. nigrior at three food levels (experiments I-VI). The food level is shown beside each curve.

This means that the functional relationship between the existing food supply and cannibalism induced by food shortage is different in the two species.

Fig. 10 illustrates the mean food consumption data for experiments I-VI. The curves in Fig. 10 offer insight into how food was being distributed among the individuals present in the populations. Dineutes nigrior is the more conservative species in its exploitation of the food supply; that is, more larvae are alive per unit of food at any time.

The sharp downward dips in the food consumption curves mark the average time when molting occurred; at these times the majority of the population temporarily ceased feeding. The molts are not always recorded due to staggering of the develop- mental rates of the individuals. The molts indicate one source of difference between the species. Recall that in Fig. 4 it was shown that horni and nigrior have nearly identical developmental rates (molting rates) when grown as isolated individuals. But, the molting times indicated by the food consumption data (Fig. 10) are not the same; nigrior molts later than horni. This is particularly well indicated in the center plot in Fig. 10. Here the first and second molts of nigrior fall almost two days later than those of horni. The same kind of difference is shown by the times for onset of pupation (P). The mechanism for this alteration of developmental rate is unknown, but it explains why nigrior has a higher age-specific survival. When experiencing a period of food short- 


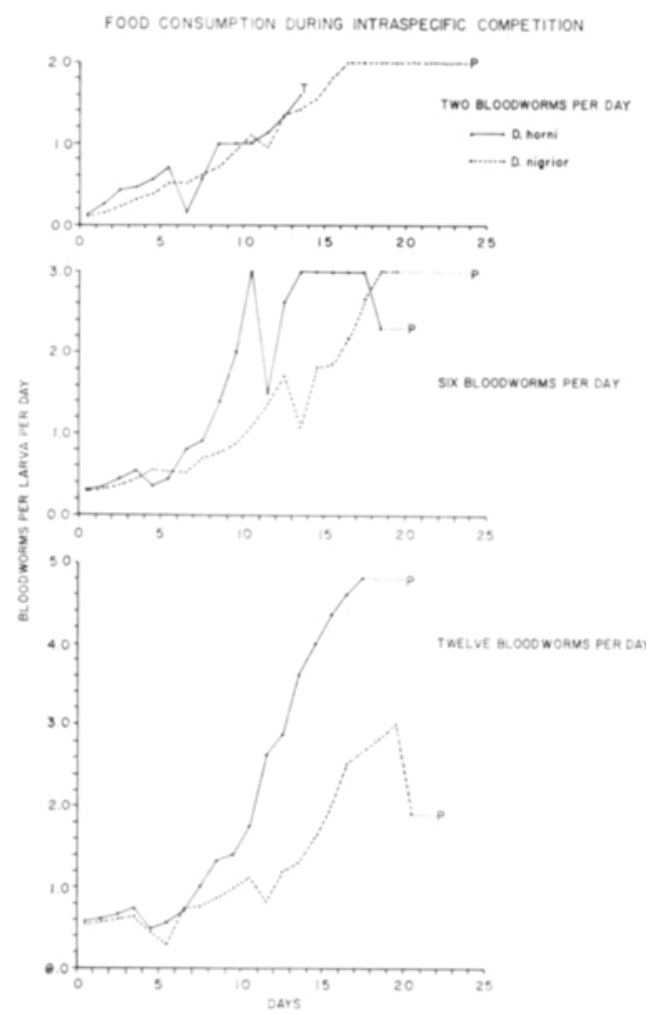

Fic. 10. Mean food consumption per larva during intraspecific competition experiments with $D$. horni and $D$. nigrior (experiments I-VI).

age, the developmental time for nigrior is extended and less use is made of cannibalism in adjusting population size to the existing food supply.

Mean survivorship curves for Dineutes assimilis at food levels of six and 12 bloodworms per day and temperatures of $20^{\circ}$ and $25^{\circ} \mathrm{C}$. are shown in Figs. 11 and 12 (experiments VIII-XI, Table 4). A curve for nigrior (experiment VII) obtained under the same conditions of bowl size and temperature is included in Fig. 11 for comparison. In these curves for assimilis the separation caused by different food levels is small, indicating that assimilis is less responsive to the food level than either of the other two species.

Mean food consumption curves for assimilis and nigrior (experiments VII, VIII, and IX) are shown in Fig. 13. It was ob- served in a number of these experiments that assimilis does not always exhaust the food supply, yet cannibalism continues.

\section{Interspecific Competition}

Table 5 outlines the experiments involving interspecific competition. Only two of the three possible combinations of the species were made. These were nigrior versus horni and nigrior versus assimilis. The decision to explore these particular combinations was based largely on field evidence (e.g., Burt Pond), from which it appeared that nigrior and assimilis were similarly different from horni. From the intraspecific data just discussed it now appears that assimilis has peculiarities of its own.

In competition between nigrior and horni, horni was always the more successful species. The upper graph in Fig. 14 describes relative abundance changes in four different kinds of experiments (XII$\mathrm{XV}$, Table 5). This graph is a plot of mean "per cent progress" (defined under Methods and Materials) of the winning species (horni) against time. The lower graph in Fig. 14 shows the total survivorship in each experiment. These experiments involve the four combinations of two different temperatures and two different initial relative abundances (shown in the legend for Fig. 14). At $30^{\circ} \mathrm{C}$. horni quickly drives nigrior to extinction. This happens even when horni is less abundant initially. At $25^{\circ} \mathrm{C}$. horni consistently excludes nigrior only when it (horni) is initially superior in numbers. When nigrior is initially the more abundant species (experiment XV, Table 5) this is not the case. In some replicates nigrior now excludes horni with the result that the mean course of the relative abundances, while still in favor of horni, does not end in the uniform exclusion of nigrior. The mean survivorship curves in the lower graph in Fig. 14 are all quite similar. However, the highest curve is also the one from the experiment where nigrior was more abundant initially and subsequently fared better.

The competition results are explicable 


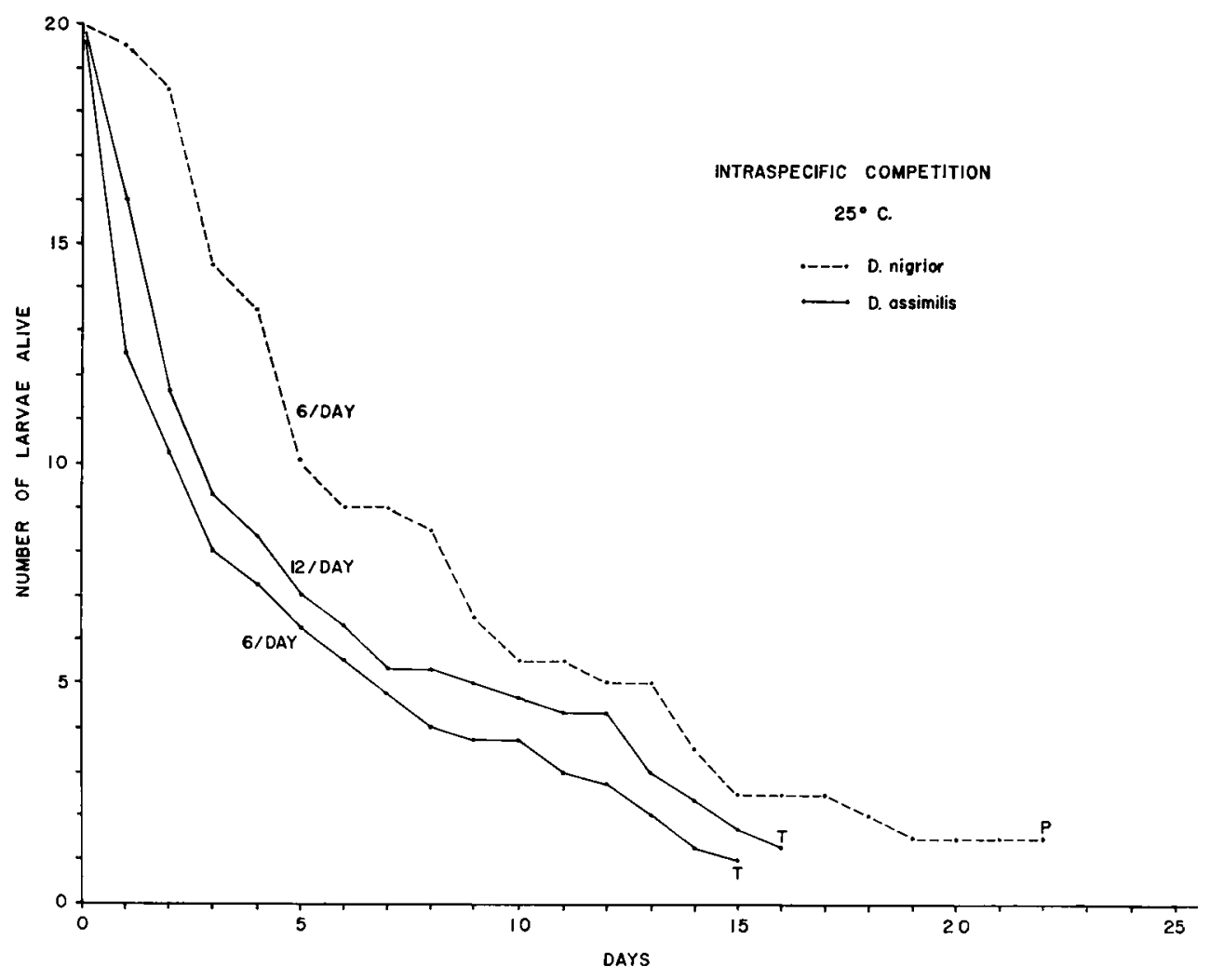

FIc. 11. Mean survivorship of $D$. assimilis during intraspecific competition at $25^{\circ} \mathrm{C}$. and two different food levels (experiments VIII and IX). A curve for $D$. nigrior is included for comparison (experiment VII).

on the basis of two facts already established: larval aggression (often leading to cannibalism) is food-dependent, and $D$. horni has a lower age-specific survival and higher per larva demand than $D$. nigrior. Therefore, when the two species are together the food per larva ratio at any instant becomes critical. When this ratio is just high enough to suppress aggression in individuals of nigrior, it is too low to cause suppression of such behavior in individuals of horni. The result of this is that the behavior of nigrior will be primarily (or at least alternately) passive while that of horni will be largely aggressive. A greater proportion of the deaths due to cannibalism thus fall to nigrior.

These behavioral considerations also explain why nigrior fares better when it is initially the most abundant species. In this case the distribution of the deaths is not so disproportionate. The greater abundance of nigrior is now enough' to hold the food per larva relationship close to that which occurs in populations consisting entirely of nigrior. As a result nigrior behavior is more generally aggressive, a much safer state to be in when horni is present. Now aggression between larvae (within or between species) will be almost uniformly reciprocal. Therefore death will fall to the species with much less of a bias in favor of horni. Apparently this only happens at $25^{\circ} \mathrm{C}$. At $30^{\circ} \mathrm{C}$. the behavioral advantage held by horni is still strong enough to overcome an initial preponderance of nigrior.

Fig. 15 is a plot of the mean "per cent progress" changes of Dineutes assimilis in four experiments (XVI-XIX, Table 5) 


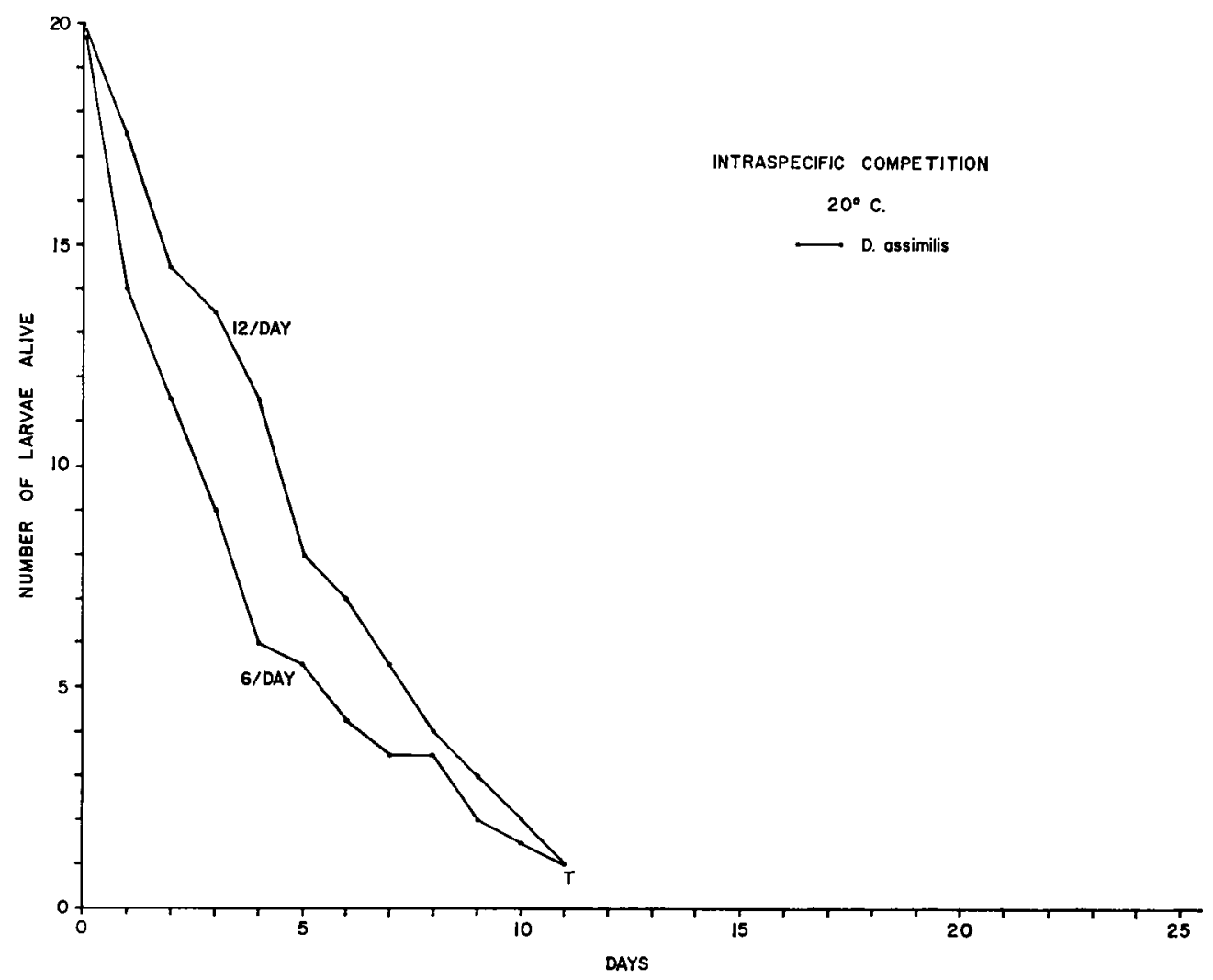

FIG. 12. Mean survivorship of $D$. assimilis during intraspecific competition at $20^{\circ} \mathrm{C}$. and two different food levels (experiments $\mathrm{X}$ and $\mathrm{XI}$ ).

involving interspecific competition with $D$. nigrior. In these, temperature $\left(20^{\circ}\right.$ and $25^{\circ}$ C.) and the initial density of the whole culture (one larva per $7.47 \mathrm{~cm}^{2}$ and one larva per $4.33 \mathrm{~cm}^{2}$ ) were varied. The species were always numerically equal at the onset.

At $25^{\circ} \mathrm{C}$. with the lower overall initial density (one larva per $7.47 \mathrm{~cm}^{2}$, experiment XVI) D. assimilis won in five days. At the same temperature but higher initial density (one larva per $4.33 \mathrm{~cm}^{2}$, experiment XVIII) the outcome became indeterminate with assimilis being only slightly more successful. If the experiment was started at the higher density but with the temperature five degrees lower (one larva per $4.33 \mathrm{~cm}^{2}, 20^{\circ} \mathrm{C}$., experiment XIX) nigrior was the winner. In the fourth combination (one larva per $7.47 \mathrm{~cm}^{2}, 20^{\circ}$
C., experiment XVII-no replication) the winner was assimilis. These experiments indicate that a five degree change in temperature can reverse the outcome of competition between nigrior and assimilis and that the total initial density can influence the relative success of the two species and possibly reverse the outcome. One set of conditions leads to indeterminate results.

The results of these latter experiments are not the obvious consequences of what is known from single species experiments and larval behavior. It seems likely that peculiarities in the behavior of $D$. assimilis are significantly involved, but the nature of the interaction is not clear.

The preceding experiments are only a few of those possible. Yet, they indicate that the species are quite different in their reactions to food limitation. Further, the 
TABLE 5. Description of experiments on larval interspecific competition.

\begin{tabular}{|c|c|c|c|c|c|c|}
\hline $\begin{array}{c}\text { Experi- } \\
\text { ment } \\
\text { number }\end{array}$ & $\begin{array}{l}\text { Species in } \\
\text { compe- } \\
\text { tition }\end{array}$ & $\begin{array}{c}\text { Initial } \\
\text { number of } \\
\text { each species }\end{array}$ & $\begin{array}{c}\text { Food level } \\
\text { (bloodworms } \\
\text { per day) }\end{array}$ & $\begin{array}{c}\text { Tempera- } \\
\text { ture } \\
\left({ }^{\circ} \mathrm{C} .\right)\end{array}$ & $\begin{array}{l}\text { Bowl size } \\
\text { (diameter } \\
\text { in } \mathrm{cm} \text {.) }\end{array}$ & $\begin{array}{l}\text { Number of } \\
\text { repli- } \\
\text { cates }\end{array}$ \\
\hline \multirow[t]{2}{*}{ XII } & D. nigrior & 26 & 6 & 30 & 19.5 & 2 \\
\hline & D. horni* & 14 & & & & \\
\hline \multirow[t]{2}{*}{ XIII } & D. horni* & 26 & 6 & 30 & 19.5 & 2 \\
\hline & D. nigrior & 14 & & & & \\
\hline \multirow[t]{2}{*}{$\mathrm{XIV}^{* *}$} & D. nigrior & 26 & 6 & 25 & 19.5 & 6 \\
\hline & D. horni & 14 & & & & \\
\hline \multirow[t]{2}{*}{$\mathrm{XV}$} & D. horni* & 26 & 6 & 25 & 19.5 & 6 \\
\hline & D. nigrior & 14 & & & & \\
\hline \multirow[t]{2}{*}{ XVI } & D. nigrior & 20 & 6 & 25 & 19.5 & 3 \\
\hline & D. assimilis* & 20 & & & & \\
\hline \multirow[t]{2}{*}{ XVII } & D. nigrior & 20 & 6 & 20 & 19.5 & 1 \\
\hline & D. assimilis* & 20 & & & & \\
\hline \multirow[t]{2}{*}{$\mathrm{XVIII}^{* *}$} & D. nigrior & 10 & 6 & 25 & 10.5 & 3 \\
\hline & D. assimilis & 10 & & & & \\
\hline \multirow[t]{2}{*}{ XIX } & D. nigrior ${ }^{*}$ & 10 & 6 & 20 & 10.5 & 4 \\
\hline & D. assimilis & 10 & & & & \\
\hline
\end{tabular}

* Species which is the exclusive winner.

** Experiment with indeterminate results.

experiments are sufficient to demonstrate that subtle developmental and behavioral differences between species can strongly influence competitive interaction.

\section{Discussion}

\section{Regulation of Population Size}

The laboratory experiments here reported suggest that food-dependent cannibalism is a potential mechanism for the regulation of larval population size in Dineutes. Such a mechanism is adaptive in that it facilitates the efficient exploitation of a fluctuating food supply. If the food supply suddenly increases, cannibalism declines as the increasing individual food requirements of the growing larvae are satisfied by the expanded food supply. If the food supply remains constant or decreases, cannibalism intensifies. In nature, fluctuations in the food available to gyrinid larvae probably do occur since so many aquatic invertebrates experience seasonal bursts of reproduction.

This modulated use of cannibalism in Dineutes contrasts with the manner in which parasitoid wasp larvae regulate population size (Salt, 1961). In wasp larvae the entire numerical decline (due to killing among the larvae) occurs in the first day of larval life. There is no reason for a delay in the regulatory process since the food supply of parasitoids comes in a form (caterpillar host) which is of a predictable amount and quality.

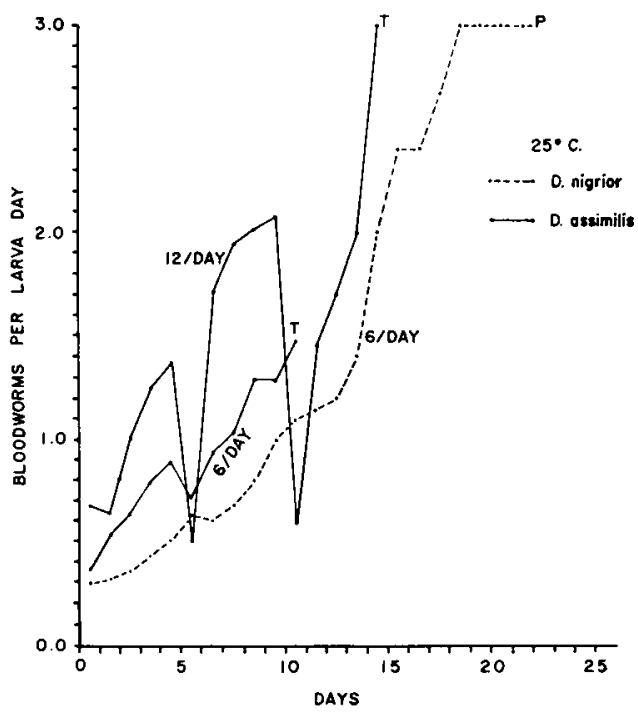

Fig. 13. Mean food consumption per larva during intraspecific competition experiments with $D$. assimilis and $D$. nigrior at $25^{\circ} \mathrm{C}$. (experiments VII-IX). 

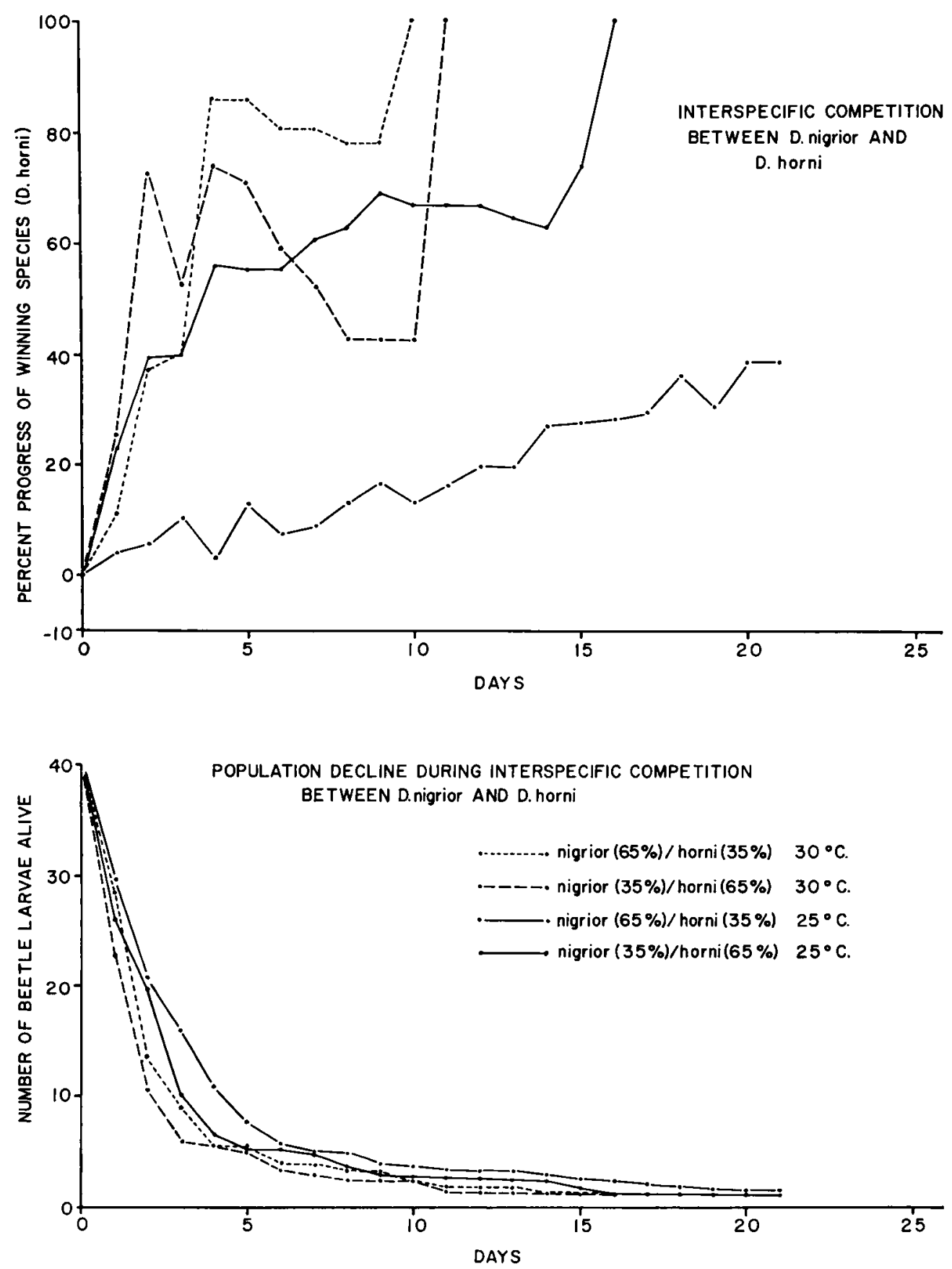

FIG. 14. Mean "per cent progress" of D. horni (upper graph) and mean total survivorship (lower graph) during interspecific competition between $D$. horni and $D$. nigrior (experiments XII-XV). The legend for both graphs is shown in the lower graph. 


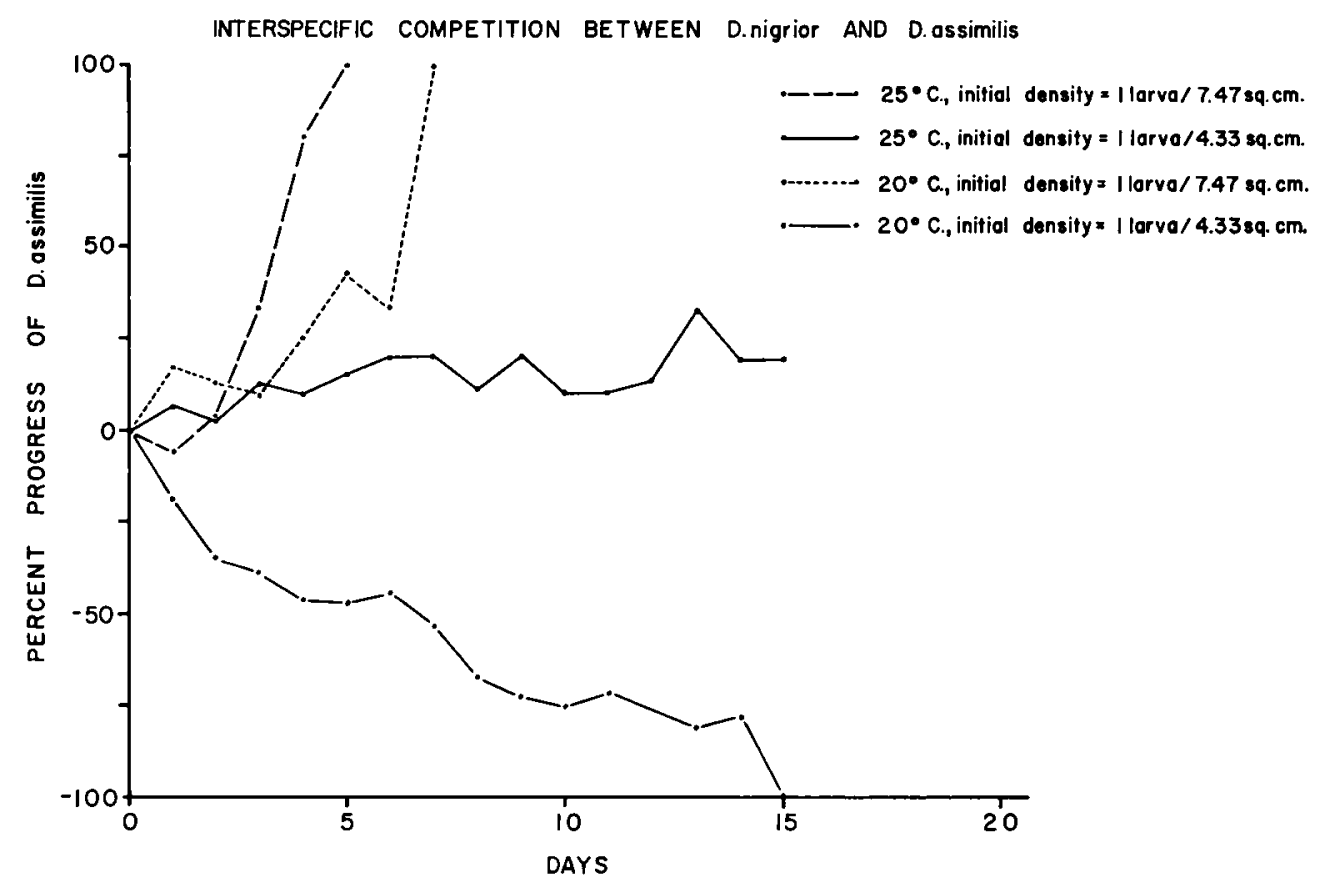

FIG. 15. Mean "per cent progress" of $D$. assimilis in four different interspecific competition experiments between $D$. nigrior and $D$. assimilis (experiments XVI-XIX).

The fact that larvae of Dineutes nigrior under a food-limited regime display a slowed developmental rate would further moderate the use of cannibalism in population regulation, and allow higher ultimate survival. This extension of larval developmental time has been found in larval competition experiments with certain species of Drosophila (Sokoloff, 1955; Miller, 1964). In Drosophila, a species which possesses this capacity has the advantage in competition with a species possessing an inflexible developmental rate. This is obviously not the case in Dineutes, where Dineutes nigrior loses to Dineutes horni. There is a fundamental difference between Dineutes competition and Drosophila competition, because cannibalism occurs among Dineutes larvae, but not among Drosophila larvae. It seems reasonable to propose that the capacity to retard the rate of larval development has evolved in Dineutes nigrior under selection favoring a "frugal" exploitation of a highly variable food supply. This capacity presumably would not evolve under conditions where the food supply was more predictable, or of short duration, or where the food supply was strongly contested for by many species. A similar explanation may or may not apply in the case of Drosophila. Sokoloff (1955) has pointed out that it remains problematic whether competition for food ever occurs in natural Drosophila populations.

The relationship between intraspecific competition and population regulation in insects has recently been reviewed in detail by Klomp (1964), and it appears that cannibalism and the slowing of developmental rate under competitive conditions occur in a number of insects.

\section{The Argument for Competition}

The field distributions of the species of Dineutes in Michigan strongly suggest that interspecific competition is a meaningful consideration. However, no single aspect 
of the distributional pattern is by itself convincing. It is the total pattern which makes competition reasonable. This pattern deviates from that expected if resource limitation and consequent competition were non-existent. If resources were not limiting to these populations, the kind of pattern found by Ross (1957) among Illinois leafhoppers would be expected. That is, most of the species would be well represented in most of the habitats. In the leafhoppers Ross suggests that local differences in abundance reflect differing capacities for population growth among the species in different microenvironments, and that interspecific competition is not a factor influencing these capacities. Since the species are very similar, the shifts in order of abundance are not usually great. Among Dineutes species the contrasts in local relative abundance are often drastic, as shown by the comparison of neighboring ponds and lakes.

The cases of coexistence found in field distributions of Dineutes species effectively close the argument for competition. In several of the localities considered in this study, it is known that a species reproduced in a place where the bulk of the population and the majority of the reproduction was that of another species. If a less successful species is capable of reproduction in such a situation it is likely that it could develop a larger population there if it were the only species present. The condition insisted upon by Park (1954) seems to be fulfilled: each of the species could live in the habitats dominated by another species. However, Park's condition is not rigorously satisfied because, as pointed out above, observation alone cannot separate independent life history phenomena from interacting life history phenomena. The finding of a certain number of teneral beetles of a non-dominant species may merely represent the best that species could do in that particular place irrespective of the presence of other similar species.

The natural history of Dineutes is in agreement with the idea that competition is a frequent occurrence. Their carnivorous and scavengering habits, combined with evidence that they are relatively unavailable to predators, makes resource limitation likely. Furthermore, breeding occurs while the adults are highly concentrated with the result that the eggs and newly hatched larvae are also strongly clumped. This would suggest that resource (probably food) limitation and competition are likely to be most intense during larval growth.

The foregoing constitutes an attempt to establish the importance of competition by argument. As such it is subject to the weakness stated previously, i.e., competition is thought to be important on the basis of natural history information. The existence of competition between Dineutes species in nature remains to be demonstrated rigorously.

\section{The Question of Coexistence}

A number of habitats studied in the course of this work contained more than one species of Dineutes. In most cases only one species appeared to be really successful, but in a number of instances there was an obvious persistence of two species. Any situation where it is known that two or more of these species completed reproduction must be considered a case of coexistence. If two or more species coexist in a competitive situation this may be due to: (1) an intermediate environment consisting of a combination and fluctuation of variables such that no species is uniquely and consistently favored; or (2) it may be due to spatial environmental heterogeneity which provides each species with a place of superiority in addition to areas of ecological overlap. Heterogeneity as used here refers to disjunct geometric properties of the environment, while intermediacy refers to a single uniform space containing a complex of varying factors such that the outcome of competition is not uniquely determined. Both of these ideas are involved in Hutchinson's (1957) niche concept. An intermediate environment corresponds to his region of niche overlap, with the added condition that the probabilities that either species 
will persist approach equality. It may be the case that in nature these probabilities need not be exactly equal due to the possibility of immigration. Hutchinson (1964) has considered similar ideas with reference to the coxistence of phytoplankton species. It seems reasonable that localized cases of coexistence might occur among competing species.

Burt Pond may be an expression of such environmental intermediacy. It appears that $D$. assimilis could maintain itself indefinitely in this pond either by occasionally encountering more favorable years or by a yearly addition of overflow individuals from other more advantageous habitats.

Environmental heterogeneity on a small scale (within a single body of water) might be considered a sufficient explanation for natural coexistence, except for the fact that a complex pond (Burt Pond), a simple pool (Pond No. 5, Table 3), and a laboratory culture (experiment XVIII) all suggest the possibility of indeterminancy in competition between $D$. nigrior and $D$. assimilis. Similar results have been found in the extensive Tribolium experiments of Park (1957).

Coexistence among Dineutes species appears in different degrees extending from situations which are almost monospecific to ones where two species are almost equal in numbers. In some of these places coexistence probably occurs year after year. Prolonged competitive coexistence may depend on environmental intermediacy on a small scale (e.g., within a single body of water) combined with environmental heterogeneity on a larger scale (e.g., differences between bodies of water in the same local area).

\section{Probable Features of Competition among Dineutes Species}

The laboratory experiments have established three facts about larval competition in Dineutes: (1) species-characteristic differences in the cannibalistic regulation of population size can determine the outcome of competition; (2) the initial concentrations of the species can alter the outcome of competition; and (3) temperature can influence or reverse the outcome of competition. These may be of significance in nature.

Species-characteristic differences in the regulation of population size through cannibalism lead to differing behavioral states under some circumstances. This is the explanation for the superiority of $D$. horni over $D$. nigrior. While it is clear that these behavioral differences are primarily an extension of the behavioral patterns observed during intraspecific competition, it is not obvious that the outcome of competition could be predicted from a knowledge of what happens during intraspecific competition. It is only after the interspecific experiments have been performed that we realize that no new information is required. Very much the same thing has been found by Polnik (1960) in a series of experiments with two species of flour beetles.

Birch (1953) found that the outcome of experimental competition between two species of grain beetles always favors the species with the highest intrinsic rate of increase. This is probably not the case with $D$. nigrior and $D$. horni, since it seems likely that nigrior (which loses in competition) has the higher rate of increase. This assumption is based on the greater survival of nigrior in single species populations and the similarity of the fecundity rates of the two species. The behavioral advantages of horni over nigrior during larval competition may be general in nature.

Despite the behavioral advantage possessed by $D$. horni, $D$. nigrior is able to persist in small ponds in southern Michigan. Here nigrior probably has the advantage due to its earlier onset of breeding and the small amount of space in which the larvae can disperse. Thus, nigrior is able to develop high initial numbers of larvae before horni breeds. The early spring period favoring nigrior may be sufficient to give this species complete dominance in many northern lakes and to allow it to maintain substantial populations in others. 
It is also possible that horni may be extending its range northward and beginning to exert competitive pressures on northern nigrior populations. If such a process is occurring it would be of interest to know whether or not it is proceeding coincident with postglacial warming.

\section{Interspecific Competition and Time}

The question of the amount of time required for interspecific competition to produce changes in natural populations is largely unexplored. Such changes must, of course, be manifested by shifts in the sizes of populations. If the sizes of competing populations rapidly alter in a reciprocal fashion over a small number (tens to hundreds) of generations this would conform well to the idea of competitive exclusion as generally conceived (e.g., DeBach, 1963). If the interaction goes more slowly and extends over a much longer span of generations (hundreds to thousands) changes will occur among the genetic determinants of the ecological attributes of the two species. The specific nature of the genetic changes need not be further specified. The point is that competition creates a situation where one species becomes the dominant feature in the selective environment of another. It seems then that coexistence is an expected condition if competition is to operate as a facet of natural selection.

With regard to the development of natural communities there is another difference between these two views of competition. In rapid competitive exclusion, one species simply displaces another. It is as if interspecific competition contributes to the formation of natural communities merely by filtering out a required number of species from a larger array of potential constituents. Once the community has formed, competition would occasionally involve the exchange of one species for another (DeBach, 1963). Conversely, competitive coexistence through its evolutionary effects would cause species to pass through increasingly stable degrees of coexistence. The contrast between these two alternatives as they are set out here becomes clear if we ask the following question. How many species out of a given set of initially competing species (with a common limiting resource) eventually become part of the community? If competitive exclusion holds perfectly the answer is one. Where a prolonged coexistence is the case the answer is not specified but it could easily be greater than one. It is not necessary to hold that only one of these alternatives is always the case. It is simply that they are different.

\section{SUMMARY}

This study involved field and laboratory investigations of three species of the genus Dineutes in an attempt to find out if distribution patterns (in Michigan) suggest that interspecific competition is relevant, and to determine possible mechanisms of competition.

Broad areas of overlap exist in the continental ranges of the three species. Seasonal aspects of their life cycles are similar with two exceptions. Dineutes nigrior and $D$. assimilis begin breeding slightly earlier than $D$. horni, and $D$. assimilis has a considerably shorter breeding season than the other two species. Egg production and larval growth are very similar in all three species. Whirligig beetles seem to be relatively free from predation.

The field study yielded a number of results. (1) Relative abundances of the three species are correlated with northsouth position. In southern Michigan, horni is dominant, but nigrior is dominant to the north. Dineutes assimilis is nearly always rare and disappears in the northernmost lakes. (2) On a local scale, in southern Michigan, horni is dominant in lakes whereas nigrior and assimilis are the usual dominants in ponds. (3) Such habitat exclusion is most marked during the breeding season. (4) Two or three of the species are known to have completed reproduction simultaneously in some localities, constituting cases of coexistence.

A number of points were established by the laboratory experiments. (1) Dineutes 
larvae are cannibalistic and the intensity of individual larval aggression is inversely related to the amount of food received. (2) Single species populations of larval Dineutes adjust numerically to the existing food supply through cannibalism. (3) Less food per individual is required to suppress cannibalistic behavior in nigrior than in horni, and assimilis is still less responsive to food level. (4) In interspecific competition between nigrior and horni, horni is the better competitor. Whenever the adjustment of the total number of larvae of both species is just low enough to reduce cannibalistic behavior in nigrior it is still insufficient to reduce such behavior in horni. The result is a disproportionate number of nigrior deaths. (5) Lower temperature and a high initial relative abundance of nigrior reduces the advantage held by horni. (6) In competition between assimilis and nigrior, assimilis usually wins but the outcome can be reversed by lower temperature and higher initial density.

It appears that in nature regulation of population size by larval cannibalism would be an adaptation for dealing with a variable food supply.

Patterns of distribution, the general natural history of Dineutes, and the likelihood that larval populations are resourcelimited make it reasonable that competition does occur in nature, although rigorous proof is lacking.

In places where coexistence occurs it may result from small-scale (small pond) environmental intermediacy such that no species is uniquely favored in competition. Heterogeneity of the environment on a larger scale may supply neighboring places where each of the species is uniquely favored. The result of these two possibilities would presumably be the observed overall pattern of habitat exclusion with occasional cases of coexistence.

It is proposed that interspecific competition acts as a selective force during coexistence and that this function of competition is distinct from the idea of competitive exclusion.

\section{ACKNOWLEDGMENTS}

I am indebted to Dr. L. B. Slobodkin and Dr. N. G. Hairston of the University of Michigan for advice and criticism throughout the study. I extend my gratitude to Dr. F. C. Evans for permission to use the facilities of the Edwin S. George Reserve of the University of Michigan and to Dr. A. H. Stockard who repeatedly made the facilities of the University of Michigan Biological Station available.

\section{Literature Cited}

Andrewartha, H. G., and L. C. Birch. 1954. The distribution and abundance of animals. Univ. Chicago Press, 782 pp.

Baldur, W. V. 1935. Bionomics of entomophagous Coleoptera. John S. Swift Co., St. Louis, 220 pp.

Batfour-Browne, F. 1950. British water beetles. Bernard Quaritch, Ltd., London, vol. 2, $394 \mathrm{pp}$.

BeAL, F. E. L. 1912. Food of our more important flycatchers. Bull. U. S. D. A., 44: 1-67.

Beauchamp, R. S. A., ANd P. Ullyott. 1932. Competitive relationships between certain species of freshwater triclads. J. Ecol., 20: 200-208.

Birch, L. C. 1953. Experimental background to the study of the distribution and abundance of insects. III. The relation between innate capacity for increase and survival of different species of beetles living together on the same food. Evolution, 7: 136-144.

- 1957. The meanings of competition. Amer. Nat., 91: 5-18.

Bowman, R. I. 1961. Morphological differentiation and adaptation in Galapagos finches. Univ. California Publ. Zool, 58: 1-302.

Broadhead, E. 1958. The psocid fauna of larch trees in northern England. J. Animal Ecol, 27: $217-263$.

Butcher, F. G. 1930. Notes on the cocooning habits of Gyrinus. J. Kansas Ent. Soc., 3: 64-66.

Connell, J. H. 1959. An experimental analysis of interspecific competition in natural populations of intertidal barnacles. Proc. XV Intern. Congr. Zool., London, pp. 290-293.

Crombir, A. C. 1945. On competition between different species of graminivorous insects. Proc. Royal Soc. Britain, 132: 362-395.

- 1946. Further experiments on insect competition. Proc. Royal Soc. Britain, 133 : 76-109.

DeBach, P. 1963. Competitive displacement between ecological homologues. Hilgardia, 34: 105-166. 
Fall, H. C. 1922. The North American species of Gyrinus. Trans. Amer. Ent. Soc., 47: 269306.

Frank, P. W. 1952. A laboratory study of intraspecies and interspecies competition in Daphnia pulicaria (Forbes) and Simocephalus vetulus O. F. Müller. Physiol. Zool., 25: 178204.

- 1957. Coactions in laboratory populations of two species of Daphnia. Ecology, 38: 510519.

Gause, G. F. 1934. The struggle for existence. Williams and Wilkins, Baltimore, $163 \mathrm{pp}$.

Gause, G. F., O. K. Nastukova, and W. W. Alpatov. 1934. The influence of biologically conditioned media on the growth of a mixed population of Paramecium caudatum and $P$. aurelia. J. Animal Ecol., 3: 222-230.

Gause, G. F., AND A. A. Wrtt. 1935. Behavior of mixed populations and the problem of natural selection. Amer. Nat., 69: 596.

Hairston, N. G. 1951. Interspecies competition and its probable influence upon the vertical distribution of Appalachian salamanders of the genus Plethodon. Ecology, 32: 266-274.

- - 1958. Observations on the ecology of Paramecium, with comments on the species problem. Evolution, 12: 440-450.

- 1959. Species abundance and community organization. Ecology, 40: 404-416.

Hairston, N. G., F. E. Smith, and L. B. SlobodKIN. 1960. Community structure, population control and competition. Amer. Nat., 94: 421-425.

Hatch, M. H. 1925. An outline of the ecology of Gyrinidae. Bull. Brooklyn Ent. Soc., 20: 101-114.

1927. Notes on the biology of Dineutes (Gyrinidae). Bull. Brooklyn Ent. Soc., 22: 27-28.

- 1930. Records and new species of Coleoptera from Oklahoma and western Arkansas with subsidiary studies. Publ. Univ. Oklahoma Biol. Surv, 2: 15-28.

Hutchinson, G. E. 1957. Concluding remarks. Cold Spring Harbor Symp. Quant. Biol., 22: 415-427.

- 1964. The lacustrine microcosm reconsidered. Am. Sci., 52: 334-341.

Hutchinson, G. E., AND E. S. Deevey. 1949. Ecological studies on populations. Survey of Biological Progress, 1: 325-359.

KLomp, H. 1964. Intraspecific competition and the regulation of insect numbers. Ann. Rev. Ent., 9: 17-40.

LACK, D. 1947. Darwin's finches. Cambridge Univ. Press, London, $208 \mathrm{pp}$.

LARkIN, P. A. 1956. Interspecific competition and population control in freshwater fish. J. Fish. Res. Board Canada, 13: 327-342.

LeConte, J. L. 1868. The Gyrinidae of Amer- ica, north of Mexico. Proc. Acad. Nat. Sci. Philadelphia, pp. 365-373.

LotkA, A. J. 1925. Elements of physical biology. Williams and Wilkins Co., Baltimore, 460 pp. [Reprinted by Dover Publications, New York, 460 pp.]

- 1932. The growth of mixed populations: two species competing for a common food supply. J. Washington Acad. Sci., 22: 461469.

Mabbott, D. C. 1920. Food habits of seven species of American shoal-water ducks. Bull. U. S. D. A., 862: 1-67.

MACARThUR, R. H. 1957. On the relative abundance of bird species. Proc. Nat. Acad. Sci., 43: 293-295.

- 1958. Population ecology of some warblers of northeastern coniferous forests. Ecology, 39: 599-619.

- 1960. On the relative abundance of species. Amer. Nat., 94: 23-36.

MAYr, E. 1963. Animal species and evolution. Harvard Univ. Press, Boston, 797 pp.

McAtee, W. L. 1918. Food habits of the mallard ducks of the U. S. Bull. U. S. D. A., 720: $1-35$.

Miale, L. C. 1895. The natural history of aquatic insects. Macmillan, London, $395 \mathrm{pp}$.

MILLER, R. S. 1964. Larval competition in Drosophila melanogaster and $D$. simulans. Ecology, 45: 132-148.

Mư̌izabié, S. 1957a. The growth of mixed populations of Chilomonas paramecium and Tetrahymena pyriformis. J. Gen. Microbiol., 16: $561-571$.

$1957 \mathrm{~b}$. The growth of mixed populations of Chilomonas paramecium and Tetrahymena patula. Quart. J. Micro. Sci., 98: 251-263.

PARK, T. 1948. Experimental studies of interspecies competition. I. Competition between populations of the flour beetles, Tribolium confusum Duval and Tribolium castaneum Herbst. Ecol. Monogr., 18: 265-308.

_-1954. Experimental studies of interspecies competition. II. Temperature, humidity and competition in two species of Tribolium. Physiol. Zool., 27: 177-238.

- 1957. Experimental studies of interspecies competition. III. Relation of initial species proportion to competitive outcome in populations of Tribolium. Physiol. Zool., 30: 22-40.

Polnik, A. 1960. Effects of intraspecific processes in competition. Physiol. Zool., 33: 42-57.

RoBerts, C. H. 1895. The species of Dineutes of America north of Mexico. Trans. Amer. Ent. Soc., 22: 279.

Ross, H. H. 1957. Principles of natural coexistence indicated by leafhopper populations. Evolution, 11: 113-129.

- 1962. A synthesis of evolutionary theory. Prentice-Hall, Inc., Englewood Cliffs, 387 pp.

Salt, G. 1961. Competition among insect para- 
sitoids (in mechanisms in biological competition). Symp. Soc. Exp. Biol., XV, 96: 119.

SIEGEL, S. 1956. Nonparametric statistics for the behavioral sciences. McGraw-Hill, London, $312 \mathrm{pp}$.

SMItH, H. B. 1926. Notes on the behavior of Dineutes americanus. Psyche, 33: 156-161.

SNedecoR, G. W. 1956. Statistical methods. Iowa State Univ. Press, Ames, 534 pp.

Sorolof, A. 1955. Competition between sibling species of the pseudoobscura subgroup of Drosophila. Ecol. Monogr., 25: 387-409.

Solomon, M. E. 1957. Dynamics of insect populations. Ann. Rev. Ent., 2: 121-142.

TansLey, A. G. 1917. On competition between Galium saxatile and Galium sylvestre on different types of soil. J. Ecol., 5: 173-179.

Thompson, W. R. 1956. The fundamental theory of natural and biological control. Ann. Rev. Ent., 1: 379-402.

UTIDA, S. 1953. Interspecific competition be- tween two species of bean weevil. Ecology, 34: 301-307.

VolterRa, V. 1926. Variations and fluctuations of the number of individuals in animal species living together. In Animal ecology, Chapman (1931), appendix. McGraw-Hill, New York, pp. 409-448.

WeTMore, A. 1924. Food and economic relations of North American grebes. Bull. U. S. D. A., 1196: 1-23.

WILliams, W. D. 1963. The ecological relationships of isopod crustaceans Asellus aquaticus L. and A. meridianus Rac. Proc. Zool. Soc. London, 140: 661-679.

Wirson, C. B. 1923. Water beetles in relation to pond fish culture with life histories of those found in fish ponds in Fairport, Iowa. Bull. U. S. Bur. Fish., 39: 231-345.

Winsor, C. P. 1934. Mathematical analysis of the growth of mixed populations. Cold Spring Harbor Symp. Quant. Biol., 2: 181-187. 